\title{
Chapter 5 \\ Education Reform Phenomenon: A Typology of Multiple Dilemmas
}

\author{
Yin Cheong Cheng
}

\subsection{Introduction}

Since the end of 1990s, there had been numerous education reforms initiated by policy-makers in different parts of the world with aims to meet the challenges from globalization, international competition, technological innovation, and economic transformation (Cheng and Townsend 2000). To a great extent, education reform has become a worldwide phenomenon or movement in the last two decades with strong policy input and implication (Zajda 2015). To countries with different cultural, social, and economic backgrounds, the formulation and implementation of education reforms for systemic changes may be different in some ways. But in general, nine common trends of these reforms at the macro, meso, site, and operational levels can be observed in many countries or areas particularly in the AsiaPacific region, such as Australia, Cambodia, PR. China, Hong Kong, India, Japan, Korea, New Zealand, Philippines, Taiwan, Thailand, and Singapore (see, e.g., Baker 2001; Caldwell 2001; Castillo 2001; Cheng 2001a, b; Rajput 2001; Rung 2001; Sereyrath 2001; Shan and Chang 2000; Sharpe and Gopinathan 2001; Suzuki 2000; Tang 2001; Townsend 2000; Yu 2001).

According to previous works of Cheng (2005a, Chap. 7) and Cheng and Townsend (2000) at the turn of new century, the main trends of systemic reforms at the macro-level include re-establishing a new national vision and educational aims; restructuring an education system at different levels; and market-driving, privatizing, and diversifying education. At the meso-level, increasing parental and community involvement in education and management is a salient trend. At the site-level,

Parts of materials in this chapter were adapted from Cheng (2005a, 2015a, b, 2017) and Cheng et al. (2016a).

Y. C. Cheng $(\triangle)$

The Education University of Hong Kong, Hong Kong, China

e-mail: yccheng@eduhk.hk 
the major trends are ensuring education quality, standards, and accountability; increasing decentralization and school-based management; and enhancing teacher quality and the continuous lifelong professional development of teachers and principals. At the operational level, the main trends include using information technology in learning and teaching and applying new technologies in management and making a paradigm shift in learning, teaching, and assessment.

These trends cover nearly all key aspects of an education system and each trend itself may involve many initiatives and efforts in policy formulation, implementation, and evaluation. It means that there may be a wide range of new initiatives and changes to be implemented in a systemic education reform. As a phenomenon, education reforms share some interesting features across countries as illustrated below.

In response to serious international competitions, when one country in a region is initiating education reforms with aims to further enhance its human capital and competitive capacity in a context of globalization and knowledge economy (Beetham and Sharpe 2013; Longworth 2013; Ramirez and Chan-Tiberghein 2003), its regional competitors also launch their reforms and initiate more changes in their education systems with a hidden agenda to outperform their counterparts in terms of growing human resources. The international rankings in performance of school education (such as PISA-OECD $(2006,2009,2012)$, etc.) or higher education (such as Times Higher Education's (2014-15) World University Rankings ) in the past two decades are in fact accelerating this tendency and driving the public concerns and policy dates about performance and reforms in education locally and internationally.

Given the above context, it is not a surprise that education reforms mutually influence and widely spread across countries and areas in the world as a part of globalization or international movements, sharing some common trends and similar patterns of reform behaviors. For example, education accountability, quality assurance review, school-based management, and marketization in education are common worldwide initiatives in education reforms (e.g., Figlio and Loeb 2011; Gawlik 2012; Keddie 2015; PISA 2011).

Assuming all initiatives' intention is good and achievable without taking the cultural and practical conditions into consideration, the policy-makers often make fundamental changes at all levels, implement many initiatives in parallel but plan to achieve them in a very short time. Probably they worry about losing their country competitiveness if they do not reform as fast as possible (Amdam 2013; Baumann and Winzar 2016; Fitzsimons 2015). This may be the reason why many countries implement so many initiatives, covering most trends of education reforms in the last two decades.

After nearly two decades, huge national resources had been invested in education reforms in most countries in the Asia-Pacific region and other in order to bring about substantial changes in many different aspects of society (Cheng and Townsend 2000; Savage and O'Connor 2015; Lee and Gopinathan 2018). Unfortunately, until now many countries or areas are disappointed with the outcomes of education reforms as well as the performance of their education systems in preparing their new generation for facing the challenges of the new century. For example, Taiwan 
started its large-scale education reforms in 1995 and Hong Kong launched its blueprint of education reforms in 2000. But after more than 15-20 years of implementation, both of them report serious frustration or failure in different key aspects of their systemic changes (Cheng 2017; Chou 2003).

Neither parents nor members of the community see the education system reformed satisfactorily as promised. Instead, they are generally confused and disappointed with the new initiatives and are increasingly losing confidence in school education. To some families, the better-offs are simply sending their children abroad for education if they can afford. Meanwhile, most school teachers and principals feel frustrated or even exhausted under great pressure. With Hong Kong as a salient example, the over competitions from marketization, the close control from accountability measures, the increasing workload from numerous parallel initiatives, the de-professionalization from over-management and monitoring, and the high pressure from uncertainties and ambiguities in education environment become some typical concerns of education reforms that potentially damage teachers' well-being and working conditions (such as being burnt-out and overburdened with unnecessary busy works, declining status of the teaching profession, and deteriorating quality of teaching and learning (Cheng 2009, 2017).

Given the education reforms have been implemented with far reaching impacts in the past two decades, it would be interesting and significant in policy analysis to know why the education reforms with so good intention at the beginning may not bring out the expected outcomes at the end, if not fail. What lessons can be learnt from the education reform phenomenon in the past decades such that we can avoid repeating the similar failures in future policy planning and implementation? In particular, what are the major concerns, tensions, and dilemmas in education reforms that the policy-makers, teachers, educators, change agents, and other stakeholders have to struggle with in formulating and implementing the reform policies?

To address these questions, this chapter aims to provide a preliminary analysis to illustrate the possible key dilemmas or tensions that potentially shape the characteristics of education reforms and affect their success and failure in implementation. It is hoped that some implications can be drawn for bridging the theoretical and practical gaps in research, policy-making, and practice in education reforms locally and internationally.

Based on the author's research on the worldwide education reform phenomenon since the end of 1990s to 2017 (Cheng 1996, 2005a, b, 2007, 2009, 2014, 2015a, b, 2017; Cheng et al. 2016a, b; Cheng and Greany 2016; Cheng and Townsend 2000), a typology of seven fundamental dilemmas in education reforms will be discussed and analyzed in this article, including (1) orientation dilemmas between globalization and localization, (2) paradigm dilemmas between the 1st, 2nd, and 3rd waves, (3) financial dilemmas between public interest and privatization, (4) resources dilemmas between parallel initiatives, (5) knowledge dilemmas in planning and implementation at different levels, (6) political dilemmas between multiple stakeholders, and (7) functional dilemmas between school-based management and central platform in education reforms. Without understanding and managing these 
multiple dilemmas and related tensions appropriately, many education reforms with good intentions may finally fail in implementation.

\subsection{Orientation Dilemmas Between Globalization and Localization}

Rapid globalization is one of the most salient aspects of the new millennium in the last two decades. How education should respond to the trends and challenges of globalization has become a major concern in policy-making in these years (Stromquist and Monkman 2014; Zajda 2015; Verger et al. 2016). In addition, facing the increasing demands for various developments of individuals and local communities in the new century, not only globalization but also localization and individualization are necessary in ongoing education reforms. Efforts and initiatives for a paradigm shift towards globalization, localization, and individualization in education have been gradually evident in some countries in recent years (Cheng 2005a, Chap. 3).

Globalization creates numerous opportunities for sharing knowledge, technology, social values, and behavioral norms and promoting developments at different levels including individuals, organizations, communities, and societies across different countries and cultures. In particular, the advantages of globalization may include the following (Brown 1999; Cheng et al. 2016a; Spring 2014; Waters 1995):

1. Global sharing of knowledge, skills, and intellectual assets that are necessary to multiple developments of individuals, local communities, and international communities;

2. Increasing opportunities for mutual support in producing synergy for various developments of countries, communities, and individuals globally;

3. Creating values and enhancing efficiency and productivity through the above global sharing and mutual support to serving local needs and human development;

4. Promoting international understanding, collaborations, harmony, and acceptance to cultural diversity across various countries and regions; and

5. Facilitating multi-way communications and multi-cultural appreciations among various groups, countries, and regions.

As strong evidence of globalization, internationalization of education, particularly higher education, has received central attention or strategic priority in international declarations, national policy statements, university strategic plans, and academic articles since the turn of new century (Knight 2014a). In general, it was often believed that the processes and results of internationalization contribute to the development of student global competences, economic competitiveness, income generation, national soft power building, modernization of the tertiary education sector, and transformation towards a knowledge/innovation society (Altbach and 
Knight 2007; Knight 2014b; Mohsin and Zaman 2014; Yeravdekar and Tiwari 2014). The number of international students studying in overseas universities has grown by leaps and bounds in different parts of the world, and international education has become a booming business in the past two decades (Institute of International Education 2008a, b, c, 2014). Recently it was projected that the number of international students will grow from 4.5 million in 2012 to 8 million in 2025 (OECD 2014).

Globalization or internationalization seems to be unavoidable to many countries, and numerous related initiatives have been made in education reforms with aims at taking opportunities to develop their societies and people in the process of globalization. However, in recent years, there are also increasing worldwide concerns about the negative impacts of globalization on indigenous and national developments (Cheng 2005a, Chap. 3). Various social movements and demonstrations have been initiated against the threats of globalization particularly on developing countries (Porta et al. 2015; Fominaya 2014; Martell 2016). It is believed that the dangerous consequences of globalization are various types of political, economic, and cultural colonization and overwhelming influences of advanced countries to developing countries and the rapidly increasing gaps between rich areas and poor areas in the world. In particular, the potential negative impacts of globalization include the following (Brown 1999; Stiglitz 2002; Waters 1995; Martell 2016):

1. Increasing the technological gaps and digital divides between advanced countries and less developed countries that are hindering equal opportunities for fair global sharing;

2. Creating more apparently legitimate opportunities for a few advanced countries to economically and politically colonize other countries globally;

3. Exploiting local resources (including physical resources and human talents) and destroying indigenous cultures of less advanced countries to benefit a few advanced countries;

4. Increasing inequalities and conflicts between areas and cultures; and

5. Promoting the dominant cultures and values of some advanced areas and accelerating cultural transplantation from advanced areas to less developed areas.

Many people believe that education is one of the key factors that can be used to moderate some key impacts of globalization from negative to positive and convert threats into opportunities for the development of individuals and local community in the inevitable process of globalization (Green 1999; Henry et al. 1999; Jones 1999). Given the above discussion, there may be dilemmas or tensions in policy orientation between globalization and localization in education particularly for developing countries. For example, how to maximize positive effects but minimize negative impacts of globalization is a major dilemma in the current educational reforms for national and local developments.

Specifically in education, how can we foster local knowledge and human development for individual and local developments through globalization but without its negative impacts? In what way the local education systems and their practices can localize the global knowledge and world-class skills to develop their students' twenty-first century competence for the future in a context of overwhelming 
globalization? Unfortunately, there are not too many studies to explore these important dilemmas and issues in policy-making and vision building in the past decades even though there were numerous education reforms locally and internationally.

\subsection{Paradigm Dilemmas in Education Reforms}

Since 1980s worldwide education reforms have undergone three waves of change including the effective education movement, the quality education movement, and the world-class education movement. According to Cheng (2005a), each wave of reform works within its own paradigm in conceptualizing the nature of education and formulating related initiatives to change educational practices at the operational, site, and system levels. In the transition from one wave to the next, paradigm shifts may occur in the conceptualization and practice of learning, teaching, and leadership (Abbas et al. 2013; Beetham and Sharpe 2013; Cheng 2011, 2014; Cheng and Mok 2008; Kiprop and Verma 2013).

These three paradigms in education differ from each other in terms of their assumptions about the environment, reform movements, the conception of effectiveness, the role of educational institutions, and the nature of learning and teaching (Cheng 2015b) (Table 5.1).

The First Wave. Effective education movements represent the first wave of education reforms aiming at improving internal processes in learning, teaching, and management and enhancing the internal effectiveness of educational institutions in achieving preplanned education aims and curriculum targets (Cheng 2011). Numerous initiatives targeted at internal improvements including changes in school management, teacher quality, curriculum design, teaching methods, approaches to evaluation, resourcing, and teaching and learning environments (Cheng 2005b; Ghani 2013; Gopinathan and Ho 2000; Kim 2000; MacBeath 2007).

In the first-wave paradigm, the major role of an educational institution is the delivery of planned knowledge, skills, and cultural values to students in a stable industrial society. This paradigm assumes that learning is a process in which students are mainly trainees receiving a planned set of knowledge, skills, and cultural values for their survival in society. The role of the teacher is mainly perceived as that of knowledge deliverer or instructor (Cheng 2014).

The Second Wave. In response to concerns about the educational accountability to the public, the education quality that satisfies stakeholders' expectations, and the marketization of education provision in the 1990s, a paradigm shift from the first wave to the second wave of education occurred in different parts of the world. Various education reforms were initiated to ensure the quality, accountability, and competitiveness of education provision to meet the needs of internal and external stakeholders (e.g., Figlio and Loeb 2011; Gawlik 2012; Keddie 2015; PISA 2011). A growing trend of education reforms towards quality education or competitive schools emphasized quality assurance, school monitoring and review, parental choice, student coupons, marketization, parental and community involvement in 


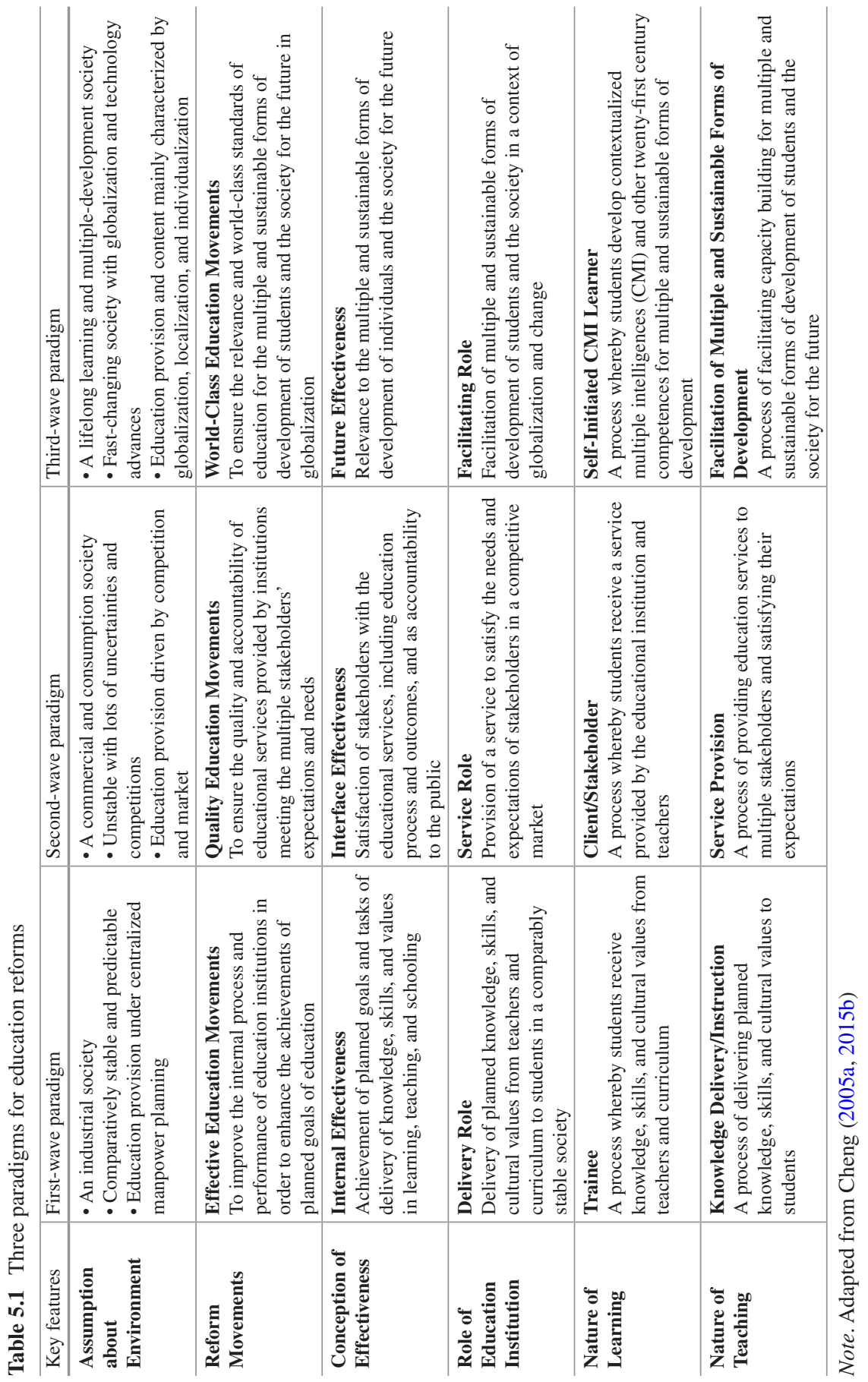


governance, and performance-based funding (Cheng 2015b; Cheng and Townsend 2000; Mukhopadhyay 2001; Pang et al. 2003).

In the second wave, the role of educational institutions is the provision of educational services in a commercial and consumer society, with quality satisfying the expectations and needs of key stakeholders-students, parents, employers, and other social constituencies. This wave emphasizes interface effectiveness between educational institutions and the community, typically defined by stakeholders' satisfaction, accountability to the public, and competitiveness in the education market. Learning is assumed to be a process for students as clients or stakeholders who receive a service provided by teachers and then become competitive in the job market. The teacher is perceived as an education service provider.

The Third Wave. Since the turn of the new century, a third-wave paradigm for education reforms has been emerging, with a strong emphasis on future effectiveness, often defined as the relevance of education to the future development of students and of the society. Given the strong implications of globalization and international competition, the new wave of reforms is driven by the notion of worldclass education movements. Educational performance is often studied and measured in terms of world-class standards and global comparability to ensure that the future of students is sustainable in this challenging and competitive era.

The third-wave paradigm embraces the key elements of contextualized multiple intelligences (CMI), globalization, localization, and individualization in education (Cheng 2015b; Maclean 2003; Baker and Begg 2003). Many initiatives pursue new aims in education, develop students' CMI or twenty-first century competencies for sustainable development, emphasize lifelong learning, facilitate global networking and international outlook, and promote the wide application of ICT in education (Finegold and Notabartolo 2010; Noweski et al. 2012; Salas-Pilco 2013; Kaufman 2013). In the third wave, learning is treated as the process whereby students as selfinitiated CMI learners develop their CMI and high-level or twenty-first century competencies to participate in multiple and sustainable forms of development in a fast-changing era. The role of the teacher is that of a facilitator of students' multiple and sustainable forms of development.

Paradigm Dilemmas. Given that the paradigms of the three waves of education reforms are fundamentally different as mentioned above, there are some paradigm dilemmas in formulation and implementation of education reform policies as illustrated below.

Some policy-makers and educators may be ignorant of the key characteristics of different paradigms that are used to conceptualize education reforms. They often directly adopt the new initiatives from the popular trends of education reforms in the world without understanding if the related paradigm is socially, culturally, and technically appropriate to their existing contextual conditions, development stage, and societal background. In other words, there may be paradigm dilemmas between the adopted reforms and the contextual background, resulting in frustrating the implementation of education reforms at different levels.

Paradigm dilemmas between the implemented change initiatives and the planned aims and goals in education are also common, hindering the success of education 
reforms. For example, ignorant of the paradigm gaps between the second wave and third wave, the policy-makers in Hong Kong have implemented a wide range of the second-wave initiatives (such as marketization, competition, and accountability measures) with targets to achieve the aims and goals of the third-wave education. The education reforms have created a lot of conflicts and frustrations in implementation in the last 16 years (Cheng 2017, 2018). How to reduce this kind of paradigm dilemmas or gaps and ensure the alignment between initiatives and aims within the same paradigm should be an important issue in planning and implementation of education reforms.

The paradigm shifts from one wave to another involve not only technical or operational changes but also ideological and cultural changes at the individual, group, site, and system levels. The transition is quite complicated and dynamic, involving different types of dilemmas and tensions to be managed and tackled. For example, how can involved parties change their original patterns of thinking and practice from the first- or second-wave paradigm to the third-wave paradigm? What are the major conditions or driving forces to make such a paradigm shift possible and successful? What are the major characteristics and best practices of paradigm shifts in learning, teaching, and leadership, locally and internationally? What are the major problems in leading paradigm shifts at different levels of education? All these and similar questions suggest unexplored areas for investigation (Cheng 2015b).

\subsection{Financial Dilemmas Between Public Interest and Privatization}

In general, policy-makers are often facing tight financial constraints in making policies to meet the fast-increasing diverse needs of local or national developments in an era of globalization, international competition, and social transformation. Given the limitation of scarce public resources, the financing models may be different to serve different purposes, such as public interest and private benefit (Labaree 1997; Bloom et al. 2007; Le Grand and Robinson 2018). There are often dilemmas in education reforms on financing education and also controversies on what education services belong to public interest but not just private benefit.

In education reforms, it seems quite often that policy-makers try to change the financial model of education from the exclusive public funding model to privatization or marketization as one major approach to expanding the sources of resources for diversifying and improving education to meet the increasing expectations. For example, China, being caught in the stream of development with its market economy playing an increasingly important role, is confronting more complicated and tighter financial constraints in developing its education system to satisfy the huge and diverse needs for education (Tang and Wu 2000; Smith and Joshi 2016).

Particularly when more and more people want to pursue higher education in order to survive in a very competitive job market, the privatization of tertiary educa- 
tion will inevitably become more common in, for example, Korea, Taiwan, Japan, PR China, and the Philippines. It is generally believed that privatization will allow educational institutions to increase their flexibility of use of physical and human resources. How to create a market or semi-market environment for promoting competition between educational institutions has become a salient issue in reform. Some countries (e.g., Australia) experimented with funding methods designed to encourage self-improvement as well as competition among schools. Other areas (e.g., Hong Kong and Singapore) tried out different types of parental choice schemes (Taylor 2018; Böhlmark et al. 2016).

Whether the shift in financing model can ensure equity and quality in education for students in general and those disadvantaged in particular is a crucial concern in policy-making of education reform. It is often perceived by the public that marketization or privatization in education may prefer those rich but disadvantage those poor in getting good education opportunities. Therefore, how to ensure those disadvantaged having equal opportunities for quality education in the new funding policy is a typical issue for debate in many developing countries in the Asia-Pacific Region (Cheng et al. 2002b).

Public education has multiple roles to serve the national aims and visions in addition to equipping students for their future (Cheng and Yuen 2017). But the privatized education may be driven by the market forces instead of the national aims, and therefore, there may be a dilemma or tension between the market force and the national agenda. As such, how can policy-makers and educators ensure that the market forces at the local or community level are in operation in line with national development? To what extent a policy framework should be set for privatization in line with national development but without hindering the market initiatives in developing education?

In planning education reforms related to funding model changes, all the above issues and dilemmas should be studied and addressed with an appropriate balance between public interest and privatization and between equity and quality in education.

\subsection{Resources Dilemmas Between Parallel Initiatives}

As mentioned previously, there were nine trends of education reforms at the four levels, including numerous new initiatives. In the last two decades, many policymakers were eager to make systemic changes implementing many initiatives in parallel in a very short time.

Any education reform often requires huge resources. The larger it is in scale, the more resources it needs. However, available resources are often limited, in particular the valuable manpower, expert experience, and available time. In particular, the large-scale curriculum and examination reforms require implementation within a short time and consequently extra and huge costs. But who will pay such costs? Besides, education reforms are always intended to achieve some noble goals of 
parallel initiatives all together, such as equality, fairness, efficiency, effectiveness, inclusiveness, accountability, and meeting individual needs of every student. However, front-line teachers and students are expected to achieve these high sounding goals with limited resources and support. They are required to carry out many new initiatives despite their time and ability in serious constraint. As a result, they are exhausted and frustrated, failing to cope with the changes and finally such education reforms become chaos. These are resources dilemmas between limited resources and numerous parallel initiatives, limiting the successful implementation of systemic reforms.

The bottleneck effect in education reform of Hong Kong may provide a profound example to further illustrate the impacts of resources, dilemmas, and conflicting parallel initiatives on systemic changes (Cheng 2009, 2015a). The bottleneck effect is the situation that any new education initiatives with good will can become additional burdens on teachers and schools and the initiatives themselves also jam or block at the "bottle-neck" and hinder the implementation of other new reforms, as illustrated in Fig. 5.1. The more reforms initiated, the more hindrance jammed at the "bottle-neck" and the more pressure on teachers and schools. Why did such "bottleneck effect" happen in the Hong Kong educational reforms?

Before the reforms, the workload of Hong Kong teachers was already very high, more than 30 lessons (normally 40 min each) each week. Also, the number of students in each normal class was often in a range of 35-40. Such high workload and large class size set a very tight constraint on Hong Kong teachers' teaching approaches and strategies. Unfortunately, the initiated education reforms had paid no attention to this structural constraint that became the structural part of the "bottleneck" hindering the change of teaching and learning towards high-quality education (Cheng 2015a).

To reduce the labelling effect, the reforms converted the classification of academic quality of student intake to secondary schools from five bands to three bands such that the individual differences were drastically increased within each school and within each class in a very short period. Inevitably this structural change largely increased the difficulties and burdens on teachers' teaching and taking care of students' development.

As one of new initiatives, the implementation of inclusive education without sufficient support package also immediately and largely increased the individual differences within class and related difficulties on teachers' work. This structural change also further requested more efforts, time, and energy from teachers.

The new initiatives on implementing school-based management, school-based curriculum, school-based innovations, and integrated curriculum requested nearly all teachers to give up their familiar teaching materials, methods, curriculum, and styles and start from the beginning to prepare new teaching curriculum and materials according to the new curriculum framework and school-based needs. The challenges, difficulties, and work pressure were inevitably increased very much beyond teachers' capacity.

With the existence of "bottle-neck" in school education, many new initiatives with very good intention had become heavy burdens to teachers and schools and 


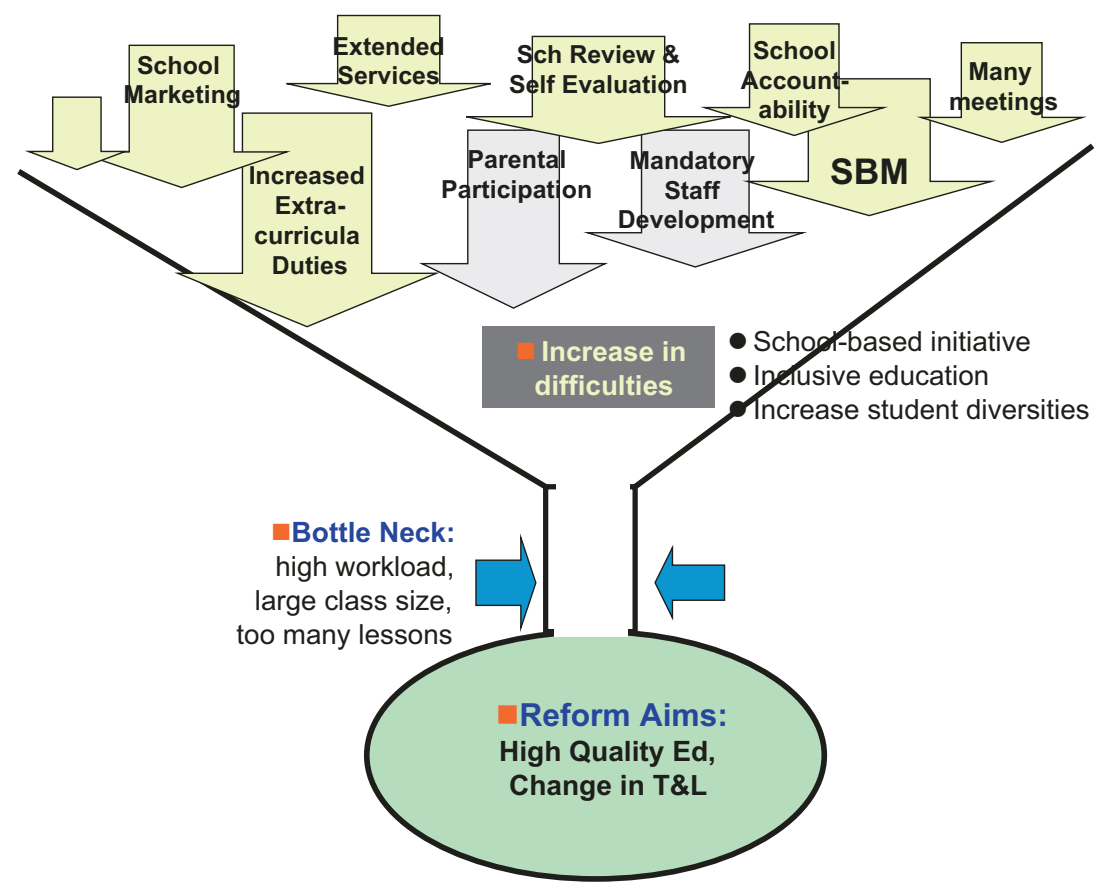

(adapted from Cheng, 2015)

Fig. 5.1 Bottle-neck effect in Hong Kong education reforms. (Adapted from Cheng 2015a)

were finally "jammed" at the bottle-neck. As shown in Fig. 5.1, these initiatives included school self-evaluation, external school review, parental involvement in school management, school marketing in the local community, extended professional services to parents and the community, more responsibilities of co-curricular activities, various types of quality assurance measures and reporting, and teacher participation in school-based management and development.

Given multiple and parallel initiatives in education reforms competing for teachers' time and energy in implementation, how the policy-makers and change agents address the above resources dilemmas and the related difficulties created by bottleneck effects should be a crucial issue related to the success and failure of a systemic education reform. 


\subsection{Knowledge Dilemmas in Planning and Implementation at Different Levels}

As mentioned above, the education reforms often change the key aspects of the whole education systems involving many new initiatives. The scope of reforms is so huge, and the nature of changes is so fundamental, and therefore, a strong and comprehensive knowledge system is really needed to support formulation and implementation of such large-scale reforms and their numerous related initiatives at different levels of the education system and at different stages of development and change. Unfortunately, there is often absence of such a strong knowledge system to support the related policy planning and implementation. Why?

Let the author use the case of Hong Kong to illustrate the problems in using knowledge for education reforms. In Hong Kong there was an intended strategy to use research to inform policy-making before the large-scale education reform, including that outlined in the Education Commission (1997) Report No. 7: "draw reference from experiences and research materials in and outside Hong Kong; research into specific issues related to the review."

In practice, however, research-based policy development was a rarity and luxury in Hong Kong (Cheng et al. 2002a). For example, the Education Commission had a very tight schedule of just 1-2 years but had to review the whole education system and make numerous recommendations in 1999-2000. It was really a dilemma between using research and knowledge to inform education reforms, the large scale of education reforms, and the urgency (tight schedule) of reform implementation. What kind of research and knowledge could they expect except their own experiences and ideas as well as some overseas experiences without rigorous analysis? There was lack of a comprehensive and relevant knowledge base to support policy development and implementation of large-scale and influential reforms in such a short period (Cheng 2005a, Chap. 8, 2017).

Hong Kong is a small place with population of around seven million. While there are some tertiary institutions, only four of them have faculties or departments of education. The numbers of academic staff, experts, or researchers in different areas of education were in fact too small when compared with the large-scale of education reforms and the numerous areas of education at different levels to be reformed. In other words, there might not have the critical mass of education expertise in each key area to provide the necessary expertise, intelligence, and knowledge base to support reforms. In particular, there was also absence of any centrally established research institute to coordinate these separated research and expertise forces to serve the multiple and parallel initiatives in reforms.

The advisory or steering committees in Hong Kong education have involved tertiary scholars, school practitioners, and community leaders as members to contribute advices and ideas to policy-making of education reforms. Their chairmen were often business or non-education leaders appointed by the Government. This arrangement was a tradition to encourage wide participation and input from non-education sectors to policy-making. However in these years, the scope and nature of education 
and related reforms have become so complicated and fast changing. All these committee works became very challenging and demanding even far more than a fulltime commitment. Many key members who were successful leaders might have already several, if not many, substantial community commitments on top of their full-time jobs. From this point, we can see that the policy-making of such a largescale reform was in leadership and advice by "part-time or lay intelligence."

Since the 1990s, the top leadership of the Education Department has changed frequently from a few months to 2 or 3 years while other senior officials have been repositioned to different offices often. The bureaucratic/technocratic knowledge and intelligence that had been accumulated slowly in the past years was disappearing quickly due to the fluid personnel and frequent changes in leadership. Given the losing bureaucratic knowledge and intelligence, the development and implementation of new initiatives became more ad hoc, unstable, and unreliable and often ignored some important ecological relations in the policy environment, that finally affected the success of education reforms with so many parallel initiatives (Cheng and Cheung 1995; Cheng et al. 2002a).

From the above discussion, we can see that knowledge dilemmas that influence education reforms involve not only the availability of relevant research and knowledge, the scale of education reforms and parallel initiatives, and the urgency of reform implementation but also the critical mass of related expertise in key areas of education, the leadership by "part-time or lay intelligence," and the disappearing bureaucratic knowledge and intelligence.

\subsection{Political Dilemmas Between Multiple Stakeholders}

Education reform involves the short-term or long-term interests and concerns of multiple stakeholders such as parents, students, teachers, principals, supervisors, education officers, educators, change agents, community leaders, employers, unions, public media, and other. During the reform process, these diverse stakeholders may have different concerns, competing demands, and even conflicting expectations. They may exercise their political and social power to influence the policy-making in line with their needs. In the policy reform of medium of instruction (MOI) in Hong Kong schools, for example, there have been highly contradictory ideas and responses among stakeholders over the years, which have a significant impact on Hong Kong's development (Cheng 2017, Chap. 7). Therefore, there are often political dilemmas and struggles in education reforms that affect the direction, implementation, and outcomes of education reforms. How can multiple stakeholders have a rational and comprehensive understanding of an education reform, in order to reach a consensus despite their prejudices and established views?

For example, teachers or educators emphasize the citizenship quality of their graduates. Parents are more concerned with whether their children can pass the examinations and get the necessary qualifications for employment. Employers often doubt whether the graduates have the necessary knowledge and skills to perform at 
the workplace. In view of the above, at the system level, how should the expectations of these key stakeholders be identified and given priority in making the reform policies? At the site level, how can school practitioners handle the diversities and conflicting values of multiple stakeholders on the changes in the aims, content, processes, and outcomes of education during the education reforms? These are some examples of political dilemmas emerging at different levels, which have to be tackled and managed.

During the past several decades, parents and the community have increased expectations of education and are becoming more demanding of better school performance for their children. Also, there is an increasing demand for educational accountability to the public and to demonstrate value for money because education is mainly financed with public funds (Figlio and Loeb 2011; Gawlik 2012; Keddie 2015). Inevitably, educational leaders at the school, district, and national levels have to provide more direct avenues for parents and the community to participate in the management of the schools.

In some developed countries, such as Canada and the United States, there was a long tradition of parental involvement in their schools. In Asian areas like Hong Kong, Korea, Malaysia, Taiwan, and Thailand, people have become more aware of the importance of involving parents and local communities in school education (Wang 2000). Although there is seldom legislation in some areas to guarantee parents' involvement in school education, sentiment is growing that parents should be given this right.

In addition to parents, the local community and the business sector are also direct stakeholders in education. Their experiences, resources, social networks, and knowledge are often very useful to the development and delivery of education. From a positive perspective, community involvement in education can benefit the educational institutions by providing more local resources, support, and intellectual input, particularly when facing the increasing but diverse demands for quality education. Also, parents and community leaders can share the management responsibilities; strengthen communications between families, the community, and the schools; motivate teachers; monitor school operations; and even assist the school in combating negative influences inherent in the local community (Goldring and Sullivan 1996).

Even though parental and community involvement may have advantages, how to manage the related political dilemmas among multiple stakeholders and implement it effectively is still a core issue in the current education reforms. The involvement will inevitably increase the complexity, ambiguities, and uncertainties in the political domain of schools. How can school leaders be prepared to lead multiple stakeholders, build up alliances, balance diverse interests between parties and resolve conflicts of diverse interests? Would the induced political dilemmas and related difficulties from this kind of involvement in fact waste the scarce time and energy of teachers and leaders from their central education work with students?

Most Asian countries lack a culture of accepting and supporting the practice of parental and community involvement. Teachers are traditionally highly respected in the community. It is often believed that school education should be the sole respon- 
sibility of teachers and principals. Parents have tended to view them as the experts in education. Parental and community involvement is often perceived as the act of distrust towards teachers and principals; to involve parents can be perceived as a loss of face among professionals. How the policy-makers and educators can change this culture and tackle the political dilemmas to encourage more parental and community involvement is still an important concern in policy making and reform implementation.

\subsection{Functional Dilemmas Between School-Based Management and Central Platform}

The emerging international trend in educational administration moving from external control to school-based management for an effective use of resources and promoting human initiatives in education was evident in the 1990s and is continuing today. Centralized management often ignores school-based needs and human initiatives that it is often too rigid to meet changing school needs (Cheng 1996). As one of major trends worldwide, the movement of decentralization in education seeks to facilitate school-based initiatives for the development and effectiveness in education (Townsend 2000; Kim 2000; Lee 2000; Gopinathan and Ho 2000); Tang and Wu 2000).

In practice, there are some functional dilemmas between school-based autonomy and external control. For example, after decentralizing authority and power to the school-site level, how can the self-managing schools and teachers be kept accountable with respect to the quality of their provided education and their use of public money? It is often a dilemma in policy-making and practice between decentralization and accountability.

Another functional dilemma commonly appears between school-based management and equality in education. People often believe that with a greater autonomy, better schools may take the advantage to recruit better students and teachers and get better opportunities and more external resources for education. Therefore, it will increase educational inequality for those disadvantaged students (Townsend 1996).

One more functional dilemma is between school-based initiative and piecemeal knowledge. Since the implementation of school-based management, schools are assumed to develop, manage, and improve their activities and operation by themselves. Many schools and teachers often scratch from beginning to accumulate their experience and knowledge particularly when they make any school-based innovations in education. For example, many schools in Hong Kong develop their own multimedia materials and software for teaching and learning. Even though teachers are very committed and spend a lot of time to learn, prepare, and produce the materials, unfortunately the quality of materials is not so good and the technology and knowledge they use and accumulate are so thin, piecemeal, and repeating 
other people's effort. It is so ineffective and sad if teachers' scarce time and effort are used in such a way instead of directly helping and guiding their students.

If there is a central knowledge platform supported by the state-of-the-art technology and software, world-class education resources and packages, frontier expertise knowledge and experiences, and interactive supporting team to support schoolbased initiatives, teachers can build up their initiatives for teaching and learning at a much higher professional level and at the same time can save a lot of time to develop their students. To tackle the functional dilemmas between school-based management and piecemeal knowledge, a high-level central knowledge platform should be developed to serve the following functions (Cheng 2005a, Chap. 8):

- In practicing school initiatives and education activities, teachers and students can start from a higher level intelligence platform that can provide the state-of-theart knowledge and technology. They can concentrate their energy and time to use this platform for education practice and school operation, rather than wasting their time to scratch from beginning at a lower level. Of course, from the spirit of school-based management, they have their flexibility and autonomy to decide how to use the platform more effectively to meet the school-based needs.

- Associated with various types of global and local networks, the platform can provide the critical mass of intelligence and knowledge to generate new ideas, knowledge, and technology to support education reforms and school education and ensure the relevance of the policy development and educational practice to the future.

- The platform itself can be individually, locally, and globally networked to expand the critical mass of intelligence, maximize the availability of intellectual resources, and create numerous opportunities for continuous intelligence development at different levels of education.

How to develop these central platforms and facilitate schools and teachers to perform at a high level is really a strategic issue for further exploration in current education reforms worldwide. The establishment of such a central platform is capital-intensive, intelligence/knowledge-intensive, and technology-intensive, and therefore, national, regional, and even international collaborations may be needed.

Both the central platform approach and school-based approach have their own strengths and limitations. The former can be used to raise the level of intelligence, knowledge, and technology used by all practitioners in education and to avoid piecemeal, repeating, and ineffective efforts scratching from beginning. The latter can be used to promote human initiatives in the process of learning, teaching, and management and address the diverse developmental needs at the site levels. Both are necessary and important to education reforms. 


\subsection{Conclusion: A Typology of Multiple Dilemmas}

From the above discussion, we can see that numerous education reforms worldwide experienced different types of dilemmas in policy formulation and implementation and finally resulted in various kinds of frustrations and difficulties in the last two decades. Without understanding the nature and dynamics of these dilemmas, many education reforms with good intentions may fail in implementation. To address this concern, the article discusses the trends of education reform phenomenon and related dilemmas commonly happening locally and internationally.

To summarize the above analysis of seven dilemmas, a typology of multiple dilemmas in three clusters can be presented in Table 5.2. The first cluster is entitled as "Direction Cluster," including orientation dilemmas between global orientations and local concerns and paradigm dilemmas between the first, second, and third waves. The dilemmas in this cluster mainly concern the issues and tensions related to major directions, orientations, visions, aims, conceptions, and paradigms of education reforms. The key implications drawn from the analysis of dilemmas in this cluster may be summarized as below:

- To foster local knowledge and human development through globalization but without its negative impacts;

- To localize the global and world-class knowledge to serve the local community;

- To manage gaps between the adopted reforms and the contextual background;

- To reduce paradigm gaps between the implemented initiatives and the planned aims; and

- To eliminate gaps during paradigm shifts across waves of education reforms in implementation.

The second cluster is entitled as "Support Cluster" which consists of financial dilemmas between public interest and privatization, resource dilemmas between parallel initiatives, and knowledge dilemmas in planning and implementation at different levels. This cluster of dilemmas mainly focus on the issues and tensions in allocation of resources and funding, competition for scarce resources across multiple and parallel initiatives, and use of knowledge and research in supporting education reforms and related initiatives. The common implications drawn from this support cluster for policy analysis and implementation may include the following:

- To ensure equity and quality in education while changing funding models towards privatization or marketization;

- To keep a balance between the market force and the national agenda in policy making;

- To eliminate the negative impacts of bottleneck effects by reducing and prioritizing the parallel initiatives to be implemented;

- To align and reduce multiple initiatives within the capacity of teachers and students to implement them;

- To ensure the availability of relevant knowledge and research to inform education reforms particularly those large scale; 
Table 5.2 A typology of multiple dilemmas in education reforms

\begin{tabular}{|c|c|c|c|}
\hline $\begin{array}{l}\text { Clusters of } \\
\text { dilemmas }\end{array}$ & $\begin{array}{l}\text { Types of } \\
\text { dilemmas }\end{array}$ & $\begin{array}{l}\text { Key factors } \\
\text { involved }\end{array}$ & $\begin{array}{l}\text { Implications for managing reforms and } \\
\text { dilemmas }\end{array}$ \\
\hline \multirow[t]{2}{*}{ Direction } & $\begin{array}{l}\text { Orientation } \\
\text { dilemmas }\end{array}$ & $\begin{array}{l}\text { Global orientations } \\
\text { vs. local concerns }\end{array}$ & $\begin{array}{l}\text { To foster local knowledge and human } \\
\text { development through globalization but without } \\
\text { its negative impacts; To localize the global and } \\
\text { world-class knowledge }\end{array}$ \\
\hline & $\begin{array}{l}\text { Paradigm } \\
\text { dilemmas }\end{array}$ & $\begin{array}{l}\text { First, second, and } \\
\text { third waves }\end{array}$ & $\begin{array}{l}\text { To manage gaps between adopted reforms and } \\
\text { contextual background; To reduce gaps } \\
\text { between initiatives and aims; To eliminate } \\
\text { gaps during paradigm shifts across waves }\end{array}$ \\
\hline \multirow[t]{3}{*}{ Support } & $\begin{array}{l}\text { Financial } \\
\text { dilemmas }\end{array}$ & $\begin{array}{l}\text { Public interest vs. } \\
\text { privatization }\end{array}$ & $\begin{array}{l}\text { To ensure equity and quality in education } \\
\text { while changing funding models; To keep a } \\
\text { balance between market force and national } \\
\text { agenda in policy-making }\end{array}$ \\
\hline & $\begin{array}{l}\text { Resources } \\
\text { dilemmas }\end{array}$ & $\begin{array}{l}\text { Multiple and } \\
\text { parallel initiatives }\end{array}$ & $\begin{array}{l}\text { To eliminate bottleneck effects by reducing } \\
\text { and prioritizing parallel initiatives; To align } \\
\text { multiple initiatives within the capacity of } \\
\text { teachers and students }\end{array}$ \\
\hline & $\begin{array}{l}\text { Knowledge } \\
\text { dilemmas }\end{array}$ & $\begin{array}{l}\text { Planning and } \\
\text { implementation at } \\
\text { different levels }\end{array}$ & $\begin{array}{l}\text { To ensure the availability of relevant } \\
\text { knowledge and research to inform reforms } \\
\text { particularly those large scale; To build up the } \\
\text { critical mass of related expertise in key areas; } \\
\text { To keep strong knowledge/intelligence in } \\
\text { leadership and bureaucracy for reforms }\end{array}$ \\
\hline \multirow[t]{2}{*}{ Execution } & $\begin{array}{l}\text { Political } \\
\text { dilemmas }\end{array}$ & $\begin{array}{l}\text { Multiple } \\
\text { stakeholders }\end{array}$ & $\begin{array}{l}\text { To manage the diverse needs and conflicting } \\
\text { expectations of multiple stakeholders; To } \\
\text { maximize the positive contribution from } \\
\text { participation but to minimize the negative } \\
\text { effects }\end{array}$ \\
\hline & $\begin{array}{l}\text { Functional } \\
\text { dilemmas }\end{array}$ & $\begin{array}{l}\text { School-based } \\
\text { management vs. } \\
\text { central platform }\end{array}$ & $\begin{array}{l}\text { To manage the tensions between school-based } \\
\text { autonomy and equality/accountability; To } \\
\text { develop school-based initiatives with the } \\
\text { support of central knowledge platform; To } \\
\text { build up knowledge-intensive and technology- } \\
\text { intensive central platform }\end{array}$ \\
\hline
\end{tabular}

- To build up the critical mass of related expertise to support reforms in key areas; and

- To keep strong knowledge/intelligence in leadership and bureaucracy for planning and implementing education reforms.

The third cluster is "Execution Cluster" including political dilemmas between multiple stakeholders and functional dilemmas between school-based management and central platform. The dilemmas of this cluster concern issues and tensions related to conflicts, difficulties, effectiveness and efficiency in the execution, functioning, and implementation of various education reforms and involved multiple stakeholders. The key implications from the execution cluster may be summarized as below: 
- To manage the diverse needs and conflicting expectations of multiple stakeholders;

- To maximize the positive contribution from parental and community participation but to minimize their negative effects;

- To manage the tensions between school-based autonomy and equality/accountability to the public;

- To develop school-based initiatives with the support of a high-level central knowledge platform; and

- To build up a knowledge-intensive and technology-intensive central platform with local, regional, and international collaboration.

The analysis in this article and the proposed typology of multiple dilemmas provide a preliminary conceptual framework for international educators, policy-makers, researchers, and change agents to analyze and understand the multiple dilemmas and their complicated impacts on the policy-making and implementation in the education reform phenomenon. Depending on the purposes of the policy study, the analysis of dilemmas in education reforms may focus on the key features and impacts of some selected types, clusters, or their combinations of dilemmas. Hopefully, the coming worldwide efforts of education reforms can be benefited from this typology and related analyses and implications in this chapter.

\section{References}

Abbas, Z., Bharat, A., \& Rai, A. K. (2013). Paradigm shift from informative learning to transformative learning: A preliminary study. International Journal of Innovative Research and Development, 2(12), 167-172.

Altbach, P., \& Knight, J. (2007). The internationalization of higher education: Motivation and realities. Journal of Studies in International Education, 11(3/4), 290-305.

Amdam, R. P. (2013). Management, education and competitiveness: Europe, Japan and the United States. London: Routledge.

Baker, R. (2001, February 14-16). A challenge for educational transformation: Achieving the aim of "thinking and acting locally, nationally and globally" in a devolved education system. Plenary speech presented at the International Forum on Education Reforms in the Asia-Pacific Region "Globalization, Localization, and Individualization for the Future", HKSAR, China.

Baker, R., \& Begg, A. (2003). Change in the school curriculum: Looking to the future. In J. P. Keeves \& R. Watanabe (Eds.), International handbook of educational research in the AsiaPacific region (pp. 541-554). Dordrecht: Kluwer Academic Publishers.

Baumann, C., \& Winzar, H. (2016). The role of secondary education in explaining competitiveness. Asia Pacific Journal of Education, 36(1), 13-30.

Beetham, H., \& Sharpe, R. (Eds.). (2013). Rethinking pedagogy for a digital age: Designing for 21 st century learning. London: Routledge.

Bloom, D. E., Hartley, M., \& Rosovsky, H. (2007). Beyond private gain: The public benefits of higher education. In International handbook of higher education (pp. 293-308). Dordrecht: Springer.

Böhlmark, A., Holmlund, H., \& Lindahl, M. (2016). Parental choice, neighbourhood segregation or cream skimming? An analysis of school segregation after a generalized choice reform. Journal of Population Economics, 29(4), 1155-1190. 
Brown, T. (1999). Challenging globalization as discourse and phenomenon. International Journal of Lifelong Education, 18(1), 3-17.

Caldwell, B. (2001). Setting the stage for real reform in education. Plenary speech presented at the International Forum on Education Reforms in the Asia-Pacific Region "Globalization, Localization, and Individualization for the Future", HKSAR, China.

Castillo, E. S. (2001). Educational reform: The PCER strategy and findings/recommendations. Plenary speech presented at the International Forum on Education Reforms in the Asia-Pacific Region "Globalization, Localization, and Individualization for the Future", HKSAR, China.

Cheng, Y. C. (1996). School effectiveness and school-based management: A mechanism for development. London: Falmer Press.

Cheng, Y. C. (2001a). Towards the third wave of education reforms in Hong Kong: Triplization in the new millennium. Plenary speech presented at the International Forum on Education Reforms in the Asia-Pacific Region "Globalization, Localization, and Individualization for the Future", HKSAR, China.

Cheng, Y. C. (2001b). Education reforms in Hong Kong: Challenges strategies, \& international implications. Country report at the First International Forum on Education Reform: Experiences of Selected Countries, Bangkok, Thailand, 30 July—2 August 2001.

Cheng, Y. C. (2005a). New paradigm for re-engineering education: Globalization, localization and individualization. Dordrecht: Springer.

Cheng, Y. C. (2005b). Globalization and educational reforms in Hong Kong: Paradigm shift. In J. Zaida, K. Freeman, M. Geo-JaJa, S. Majhanovich, V. Rust, \& R. Zajda (Eds.), The international handbook on globalization and education policy research. (ch. 11) (pp. 165-187). Dordrecht: Springer.

Cheng, Y. C. (2007). Future developments of educational research in the Asia-Pacific Region: Paradigm shifts, reforms and practice. Educational Research for Policy and Practice, 6, 71-85.

Cheng, Y. C. (2009). Educational reforms in Hong Kong in the last decide: Reform syndrome and new developments. International Journal of Educational Management, 23(1), 65-86.

Cheng, Y. C. (2011). Towards the 3rd wave school leadership. Revista de Investigacion Educativa, 29(2), 253-275.

Cheng, Y. C. (2014). Measuring teacher effectiveness: Multiple conceptualizations and practical dilemmas. In O. Tan \& W. Liu (Eds.), Teacher effectiveness: Capacity building in a complex learning era (pp. 17-50). Singapore: Cengage.

Cheng, Y. C. (2015a). Globalization and Hong Kong educational reforms. In J. Zajda (Ed.), Second international handbook on globalization, education and policy research (pp. 219-242). Dordrecht: Springer.

Cheng, Y. C. (2015b). Paradigm shift in education: Towards the third wave research. In L. Hill \& F. Levine (Eds.), World Education Research Yearbook 2014 (pp. 5-29). New York, NY: Routledge.

Cheng, Y. C. (2017). Education reforms in Hong Kong: Trilogy. (11 Chapters) (pp. 1-236). Hong Kong: Chung Hwa Book Co. (in Chinese).

Cheng, Y. C. (2018). What impact systemic education reforms have made on key aspects of the education systems? In J. Zajda (Ed.), Globalization and education reforms. Dordrecht: Springer.

Cheng, Y. C., \& Cheung, W. M. (1995). A framework for the analysis of educational policies. International Journal of Educational Management, 9(6), 10-21.

Cheng, Y. C., \& Greany, T. (2016). International study of school autonomy and learning: An introduction. International Journal of Educational Management, 30(7), 1166-1170.

Cheng, Y. C., \& Mok, M. M. C. (2008). What effective classroom: Towards a paradigm shift. School Effectiveness and School Improvement, 19(4), 365-385.

Cheng, Y. C., \& Townsend, T. (2000). Educational change and development in the Asia-Pacific region: Trends and issues. In T. Townsend \& Y. C. Cheng (Eds.), Educational change and development in the Asia-Pacific region: Challenges for the future (pp. 317-344). Lisse, The Netherlands: Swets \& Zeitlinger. 
Cheng, Y. C., \& Yuen, T. W. W. (2017). Broad-based national education in globalization: Conceptualization, multiple functions and management. International Journal of Educational Management, 31(3), 265-279.

Cheng, Y. C., Mok, M. M. C., \& Tsui, K. T. (2002a). Educational reforms and research in Hong Kong: A request for comprehensive knowledge. Educational Research for Policy and Practice, $1(1), 7-21$.

Cheng, Y. C., Ng, K. H., \& Mok, M. M. C. (2002b). Economic considerations in educational policy making: An simplified framework. International Journal of Educational Management, 16(1), 18-39.

Cheng, Y. C., Cheung, A. C. K., \& Ng, S. W. (2016a). Internationalization of higher education: Conceptualization, typology and issues. In Y. C. Cheng, A. C. K. Cheung, \& S. W. Ng (Eds.), Internationalization of higher education: The case of Hong Kong (pp. 1-20). Singapore, Heidelberg, New York, Dordrecht and London: Springer.

Cheng, Y. C., Ko, J., \& Lee, T. (2016b). School autonomy, leadership and learning: A reconceptualization. International Journal of Educational Management, 30(2), 177-196.

Chou, C.-I. (2003). The great experiment of Taiwan education (1987-2003). Taiwan: Psychology Publishing.

Education Commission. (1997). Education Commission Report No. 7: Quality school education. Hong Kong: Government Printer.

Figlio, D., \& Loeb, S. (2011). School accountability. In E. A. Hanushek, S. Machin, \& L. Woessmann (Eds.), Economics of Education (Vol. 3, pp. 384-416).

Finegold, D., \& Notabartolo, A. S. (2010). 21st century competencies and their impact: An interdisciplinary literature review. Transforming the US workforce development system: Lessons from research and practice. Retrieved from http://www.hewlett.org/uploads/21st_Century_ Competencies_Impact.pdf.

Fitzsimons, P. (2015). Human capital theory and education. In Encyclopedia of educational philosophy and theory (pp. 1-4). Singapore: Springer.

Fominaya, C. F. (2014). Social movements and globalization: How protests, occupations and uprisings ... London: Palgrave MacMillan.

Gawlik, M. A. (2012). Moving beyond the rhetoric: Charter school reform and accountability. The Journal of Educational Research, 105(3), 210-219.

Ghani, M. F. A. (2013). Development of effective school model for Malaysian school. International Journal of Academic Research, 5(5), 131-142.

Goldring, E. B., \& Sullivan, A. V. (1996). Beyond the boundaries: Principals, parents, and communities shaping the school environment. In K. Leithwood, J. Chapman, D. Corson, P. Hallinger, \& A. Hart (Eds.), International handbook of educational leadership and administration (pp. 195-222). Dordrecht: Kluwer Academic.

Gopinathan, S., \& Ho, W. K. (2000). Educational change and development in Singapore. In T. Townsend \& Y. C. Cheng (Eds.), Educational change and development in the Asia-Pacific region: Challenges for the future (pp. 163-184). Lisse, The Netherlands: Swets \& Zeitlinger.

Green, A. (1999). Education and globalization in Europe and East Asia: Convergent and divergent trends. Journal of Education Policy, 14(1), 55-71.

Henry, M., Lingard, B., Rizvi, F., \& Taylor, S. (1999). Working with/against globalization in education. Journal of Education Policy, 14(1), 85-97.

Institute of International Education. (2008a). Global destinations for international students at the post-secondary (tertiary) level 2007. New York: Institute of International Education.

Institute of International Education. (2008b). IIE study abroad white paper series. New York: Institute of International Education.

Institute of International Education. (2008c). Open doors: Statistics on international study mobility. New York: Institute of International Education.

Institute of International Education. (2014). Open doors: International students. Retrieved from http://www.iie.org/Research-and-Publications/Open-Doors/Data/International-Students/ Enrollment-Trends/1948-2014. 
Jones, P. W. (1999). Globalisation and the UNESCO mandate: Multilateral prospects for educational development. International Journal of Educational Development, 19(1), 17-25.

Kaufman, K. J. (2013). 21 Ways to 21 st century skills: Why students need them and ideas for practical implementation. Kappa Delta Pi Record, 49(2), 78-83.

Keddie, A. (2015). School autonomy, accountability and collaboration: a critical review. Journal of Educational Administration and History, 47(1), 1-17.

Kim, Y. H. (2000). Recent changes and developments in Korean school education. In T. Townsend \& Y. C. Cheng (Eds.), Educational change and development in the Asia-Pacific region: Challenges for the future (pp. 83-106). Lisse, The Netherlands: Swets \& Zeitlinger.

Kiprop, J. M., \& Verma, N. (2013). Teacher education and globalization: Implications and concerns in the 21st century. Educational Quest-An International Journal of Education and Applied Social Sciences, 4(1), 13-18.

Knight, J. (2014a). Is internationalisation of higher education having an identity crisis? In The forefront of international higher education (pp. 75-87). Dordrecht: Springer.

Knight, J. (2014b). International education hubs: collaboration for competitiveness and sustainability. New Directions for Higher Education, 168, 83-96.

Labaree, D. F. (1997). Public goods, private goods: The American struggle over educational goals. American Educational Research Journal, 34(1), 39-81.

Le Grand, J., \& Robinson, R. (2018). Privatisation and the welfare state. London: Routledge.

Lee, M. N. N. (2000). The politics of educational change in Malaysia: National context and global influences. In T. Townsend \& Y. C. Cheng (Eds.), Educational change and development in the Asia-Pacific region: Challenges for the future (pp. 107-132). Lisse, The Netherlands: Swets and Zeilinger Publishers.

Lee, M. H., \& Gopinathan, S. (2018). Fostering economic competitiveness, national identity and social equity through education reforms: The cases of Singapore and Hong Kong. In Globalisation and education reforms (pp. 181-203). Dordrecht: Springer.

Longworth, N. (2013). Lifelong learning in action: Transforming education in the 21st century. London: Routledge.

MacBeath, J. (2007). Improving school effectiveness: Retrospective and prospective. In T. Townsend, B. Avalos, B. Caldwell, Y. C. Cheng, B. Fleisch, L. Moos, L. Stoll, S. Stringfield, K. Sundell, W. M. Tam, N. Taylor, \& C. Teddlie (Eds.), International handbook on school effectiveness and improvement (pp. 57-74). Dordrecht: Springer.

Maclean, R. (2003). Secondary education reform in the Asia-Pacific region. In J. P. Keeves \& $\mathrm{R}$. Watanabe (Eds.), International handbook of educational research in the Asia-Pacific region (pp. 73-92). Dordrecht: Kluwer Academic Publishers.

Martell, L. (2016). The sociology of globalization (2nd ed.). New York, NY: Wiley.

Mohsin, A., \& Zaman, K. (2014). Internationalization of Universities: Emerging trends, challenges and opportunities. Journal of Economic Info, 3(1), 1-21.

Mukhopadhyay, M. (2001). Total quality management in education. New Delhi: National Institute of Educational Planning and Administration.

Noweski, C., Scheer, A., Büttner, N., von Thienen, J., Erdmann, J., \& Meinel, C. (2012). Towards a paradigm shift in education practice: Developing twenty-first century skills with design thinking. In Design thinking research (pp. 71-94). Berlin, Heidelberg: Springer.

OECD. (2014). Education at a glance: OECD indicators. Paris: OECD. https://doi.org/10.1787/ eag-2014-e.

OECD-PISA. (2006, 2009, 2012). Programmes for International Student Assessment (PISA). Retrieved from http://www.oecd.org/pisa/.

Pang, I., Isawa, E., Kim, A., Knipprath, H., Mel, M. A., \& Palmer, T. (2003). Family and community participation in education. In J. P. Keeves \& R. Watanabe (Eds.), International handbook of educational research in the Asia-Pacific region (pp. 1063-1080). Dordrecht: Kluwer Academic.

PISA in Focus. (2011). School autonomy and accountability: Are they related to student performance? Paris: OECD. 
Porta, D. D., Andretta, M., Calle, A., Combes, H., Eggert, N., Giugni, M. G., Hadden, J., Jimenez, M., \& Marchetti, R. (2015). Global justice movement: Cross-national and transnational perspectives. London: Routledge.

Rajput, J. S. (2001, February 14-16). Reforms in school education in India. Plenary speech presented at the International Forum on Education Reforms in the Asia-Pacific Region "Globalization, Localization, and Individualization for the Future", HKSAR, China.

Ramirez, F. O., \& Chan-Tiberghein, J. (2003). Globalisation and education in Asia. In J. P. Keeves \& R. Watanabe (Eds.), International handbook of educational research in the Asia-Pacific region (pp. 1095-1106). Dordrecht: Kluwer Academic.

Rung, K. (2001, February 14-16). Educational reform in Thailand: Implementation and strategy. Plenary speech presented at the International Forum on Education Reforms in the Asia-Pacific Region "Globalization, Localization, and Individualization for the Future", HKSAR, China.

Salas-Pilco, S. Z. (2013). Evolution of the framework for 21st century competencies. Knowledge Management \& e-Learning: An International Journal (KM\&EL), 5(1), 10-24.

Savage, G. C., \& O'Connor, K. (2015). National agendas in global times: Curriculum reforms in Australia and the USA since the 1980s. Journal of Education Policy, 30(5), 609-630.

Sereyrath, S. (2001). Major movements of education reform in Cambodia. Country report at the First International Forum on Education Reform: Experiences of Selected Countries, Bangkok, Thailand, 30 July-2 August 2001.

Shan, W. J., \& Chang, C. C. (2000). Social change and educational development in Taiwan, 19451999. In T. Townsend \& Y. C. Cheng (Eds.), Educational change and development in the Asia-Pacific region: Challenges for the future (pp. 185-206). Lisse, The Netherlands: Swets $\&$ Zeitlinger.

Sharpe, 1., \& Gopinathan, S. (2001, February 14-16). After effectiveness: New directions in the Singapore school system? Plenary speech presented at the International Forum on Education Reforms in the Asia-Pacific Region "Globalization, Localization, and Individualization for the Future", HKSAR, China.

Smith, W. C., \& Joshi, D. K. (2016). Public vs. private schooling as a route to universal basic education: A comparison of China and India. International Journal of Educational Development, $46,153-165$.

Spring, J. (2014). Globalization of education: An introduction. London: Routledge.

Stiglitz, J. E. (2002). Globalization and its discontents. London: Penguin.

Stromquist, N. P., \& Monkman, K. (2014). Defining globalization and assessing its implications for knowledge and education, revisited. Globalization and Education: Integration and Contestation Across Cultures, 1, 1-21.

Suzuki, S. (2000). Japanese education for the 21dt century: Educational issues, policy choice, and perspectives. In T. Townsend \& Y. C. Cheng (Eds.), Educational change and development in the Asia-Pacific region: Challenges for the future (pp. 57-82). Lisse, The Netherlands: Swets $\&$ Zeitlinger.

Tang, X. (2001, February 14-16). Educational reform and development in the People's Republic of China: Issues and trends. Plenary speech presented at the International Forum on Education Reforms in the Asia-Pacific Region "Globalization, Localization, and Individualization for the Future", HKSAR, China.

Tang, X., \& Wu, X. (2000). Educational change and development in the People's Republic of China: Challenges for the future. In T. Townsend \& Y. C. Cheng (Eds.), Educational change and development in the Asia-Pacific region: Challenges for the future (pp. 133-162). Lisse, The Netherlands: Swets \& Zeitlinger.

Taylor, C. (2018). Geography of the 'new' education market: Secondary school choice in England and Wales. London: Routledge.

Times Higher Education. (2014-15). World University Rankings 2014-2015. Retrieved from http:// www.timeshighereducation.co.uk/world-university-rankings/2014-15/world-ranking.

Townsend, T. (1996). The self managing school: Miracle or myth. Leading and Managing, 2(3), 171-194. 
Townsend, T. (2000). The challenge to change: Opportunities and dangers for education reform in Australia. In T. Townsend \& Y. C. Cheng (Eds.), Educational change and development in the Asia-Pacific region: Challenges for the future (pp. 229-266). Lisse, The Netherlands: Swets $\&$ Zeitlinger.

Verger, A., Lubienski, C., \& Steiner-Khamsi, G. (Eds.). (2016). World yearbook of education 2016: The global education industry. London: Routledge.

Wang, Y. (Ed.). (2000). Public-private partnership in the social sector. Tokyo: Asian Development Bank Institute.

Waters, M. (1995). Globalization. London: Routledge.

Yeravdekar, V. R., \& Tiwari, G. (2014). Internationalization of higher education and its impact on enhancing corporate competitiveness and comparative skill formation. Procedia-Social and Behavioral Sciences, 157, 203-209.

Yu, F. Z. (2001). Education development and reform in China. Country report at the First International Forum on Education Reform: Experiences of Selected Countries, Bangkok, Thailand, 30 July-2 August 2001.

Zajda, J. (Ed.). (2015). Second international handbook on globalization, education and policy research. Dordrecht: Springer.

Yin Cheong Cheng is Advisor (Academic Development) of The Education University of Hong Kong (EdUHK). Previously he served as Chair Professor and Vice-President (Research and Development). He was also the President of World Education Research Association (WERA) and Asia-Pacific Education Research Association (APERA). He had served as a full member of the University Grants Committee, a panel member of Research Grants Council, and a member of the Quality Education Fund Steering Committee of the Hong Kong SAR Government. Currently he is the chairman of Tin Ka Ping Foundation's advisory council. His research interest includes paradigm shift, education reforms, leadership development, school management, teacher education, and higher education. Some of his publications have been translated into Chinese, Hebrew, Korean, Spanish, Czech, Thai, and Persian languages.

Open Access This chapter is licensed under the terms of the Creative Commons Attribution 4.0 International License (http://creativecommons.org/licenses/by/4.0/), which permits use, sharing, adaptation, distribution and reproduction in any medium or format, as long as you give appropriate credit to the original author(s) and the source, provide a link to the Creative Commons license and indicate if changes were made.

The images or other third party material in this chapter are included in the chapter's Creative Commons license, unless indicated otherwise in a credit line to the material. If material is not included in the chapter's Creative Commons license and your intended use is not permitted by statutory regulation or exceeds the permitted use, you will need to obtain permission directly from the copyright holder.

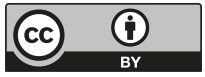

